\title{
Hypertension control: results from the Diabetes Care Program of Nova Scotia registry and impact of changing clinical practice guidelines

\author{
Cory Russell1 ${ }^{1}$, Peggy Dunbar ${ }^{2}$, Sonia Salisbury ${ }^{2}$, Ingrid Sketris*1,3 and \\ George Kephart ${ }^{1}$
}

\author{
Address: ${ }^{1}$ Department of Community Health and Epidemiology, Dalhousie University, Halifax, Canada, ${ }^{2}$ Diabetes Care Program of Nova Scotia, \\ Halifax, Canada and ${ }^{3}$ College of Pharmacy, Dalhousie University, Halifax, Canada \\ Email: Cory Russell - cjrussel@dal.ca; Peggy Dunbar - PeggyDunbar@diabetescareprogram.ns.ca; Sonia Salisbury - ssm@dal.ca; \\ Ingrid Sketris* - ingrid.sketris@dal.ca; George Kephart - george.kephart@dal.ca \\ * Corresponding author
}

Published: 20 July 2005

Cardiovascular Diabetology 2005, 4:1 I doi:10.1 186/1475-2840-4-II

This article is available from: http://www.cardiab.com/content/4/I/II

(C) 2005 Russell et al; licensee BioMed Central Ltd.

This is an Open Access article distributed under the terms of the Creative Commons Attribution License (http://creativecommons.org/licenses/by/2.0), which permits unrestricted use, distribution, and reproduction in any medium, provided the original work is properly cited.
Received: 24 April 2005

Accepted: 20 July 2005

\begin{abstract}
Background: The objective of this study was to determine the rate of blood pressure control according to 4 sets of Canadian guidelines published over a decade in patients with diabetes mellitus attending Diabetes Centres in the province of Nova Scotia.

Methods: One hundred randomly selected charts from each of 13 Diabetes Centres audited between 1997 and 2001 were extracted from the Diabetes Care Program of Nova Scotia Registry. Multivariate logistic regression analyses examined the relationship between individual characteristics and self-reported antihypertensive use. Included were II32 adults, mean age 63 years $(48 \%$ male), with 9 years mean time since diagnosis of diabetes.

Results: According to the 1992 guidelines, 63\% of the patients and according to the 2003 guidelines, $84 \%$ of patients were above target blood pressure or receiving antihypertensive medications. Forty-seven percent of patients are considered to be hypertensive and not on treatment according to 2003 guidelines. The results of the multivariate analyses showed that the only factors independently associated with anti-hypertensive use was oral anti-hyperglycemic use.

Conclusion: Hypertension is an additional risk factor in those with diabetes mellitus for macrovascular and microvascular complications. The health and budgetary impacts of addressing the treatment gap need to be further explored.
\end{abstract}

\section{Background}

Achievement of target blood pressures in hypertensive patients is often difficult. In Halifax County, Nova Scotia, $57 \%$ of men and $42 \%$ of women with hypertension were not well controlled[1]. Adequate blood pressure control is of particular concern in patients with diabetes as hyper- tension increases morbidity and mortality associated with stroke and cardiovascular disease[2,3], as well as microvascular complications such as retinopathy and nephropathy[4]. Cardiovascular disease rates have been shown to be 2-4 times higher in diabetes than in matched non-diabetic populations[5,6]. 
A Canadian study reported $43 \%$ of people (age 18-74 years) had an optimal blood pressure $(<120 / 80 \mathrm{mmHg})$, and of those with a diagnosis of hypertension, only $13 \%$ were below target (defined as $140 / 90 \mathrm{~mm} \mathrm{Hg}$ ). In this study, about $50 \%$ of patients with diabetes were hypertensive, and of these only $9 \%$ were under control[7]. An internal review at the Diabetes Care Program of Nova Scotia (DCPNS) from 1997-2001 showed that only $27.5 \%$ of a random selection of patients attending Diabetes Centres fell within the recommended target blood pressure for people with a diagnosis of diabetes $(<130 / 85 \mathrm{~mm} \mathrm{Hg})$ [8].

The United Kingdom Prospective Diabetes Study (UKPDS) emphasized the need for adequate blood pressure control in type 2 diabetes. The evidence suggested that good blood pressure control may be as important if not more important than blood glucose control in reduction of the cardiovascular complications $[3,9,10]$. Further, adequate blood pressure control in the UKPDS decreased risk for multiple diabetes end-points: $32 \%$ in deaths related to diabetes; $44 \%$ decreased risk of stroke; and a $34 \%$ reduction in risk for all macrovascular diseases, as well as a significantly decreased risk for other complications. [4] Clinical trials and epidemiologic studies have suggested the target blood pressure goal of $<130 / 80$ $\mathrm{mmHg}[11-14]$.

The treatment of hypertension in patients with diabetes has changed over the last decade. Studies and Clinical Practice Guidelines for the management of hypertension in patients with diabetes suggest lower blood pressure targets for diagnosis and control than for the general population[11,15-17].

This study determined the degree of blood pressure control in patients with diabetes according to four sets of Canadian Clinical Practice Guidelines published between 1992 and 2003[2,18-20] and described demographic and treatment variables associated with antihypertensive treatment.

\section{Methods}

The cohort was selected as part of a DCPNS (Diabetes Care Program of Nova Scotia) internal audit of approximately 100 records from each of 13 Diabetes Centres between 1997 and 2001. All patients were referred to the Diabetes Centre following a diagnosis of diabetes by a physician. Information gathered included: age, gender, weight, blood pressure, duration of diabetes, serum creatinine, urinary protein and specific antihypertensive treatment regimens. The mercury sphygmomanometer was used for blood pressure measurement and recorded by nurses and averaged over all visits for all individuals. The nurses were aware of the correct procedure for obtaining a blood pressure measurement, and performed the procedure regularly. Eligibility criteria for the cohort included being a non-pregnant adult over the age of 19; a diagnosis of type 1 or 2 diabetes; a visit to the centre within 12 months of the audit date; and at least 15 months of followup.

The final cohort included 1132 subjects. The population consists of both genders ( $48 \%$ male), with an average age of 63 (SD 12). Over $95 \%$ of patients had type 2 diabetes, and the average length of time since diagnosis was 9.3 (SD 8 ) years previous. Average scores were obtained for most tests and attributes. Kidney function was estimated using both Couchoud cutpoints and the Cockroft-Gault formula $[21,22]$ Drug information was reclassified using the WHO Anatomical Therapeutic Chemical (ATC) categories[23]. Prevalence of hypertension and trends in Clinical Practice Guidelines over time were determined.

Guidelines used for analysis included the following: 1992 Clinical Practice Guidelines for Treatment of Diabetes Mellitus - hypertension subcategory [18]; 1998 Clinical Practice Guidelines for the Management of Diabetes in Canada - hypertension subcategory [2]; 1999 Canadian Hypertension Society Recommendations for the Management of Hypertension - diabetes subcategory [19]; 2003 Canadian Hypertension Society Recommendations for the Management of Hypertension - diabetes subcategory[20].

Hypertension was defined using anti-hypertensive drug use and blood pressure records. Patients with any antihypertensive drug use and/or average blood pressure above the guideline cutpoints (systolic, diastolic, or both) were designated to be hypertensive. Rates and risk factors for hypertension were calculated for each specific guideline. Logistic regression was performed to determine predictors of antihypertensive treatment.

SAS version 8.2 (SAS Institute, Cary, NC, USA, 2001) was used for analysis.

\section{Results}

The use of the 2003 guidelines (target blood pressure: systolic $<130 \mathrm{mmHg}$; diastolic $<80 \mathrm{mmHg}$ ) increased the percentage of patients not meeting target to $84 \%$ from 63\% using 1992 guidelines (target blood pressure: systolic $<140 \mathrm{mmHg}$; diastolic $<90 \mathrm{mmHg}$ ). Those considered to be hypertensive and not on treatment increased to $47 \%$ using the 2003 guidelines from 26\% with the 1992 guidelines. (Figure 1); Clinical Practice Guidelines Effects on Nova Scotia Patients with Diabetes Classified as Hypertensive; Blank cells indicate that the category was not applicable for that guideline. The "Isolated Systolic" category in the 1999 and 2003 guidelines is used 


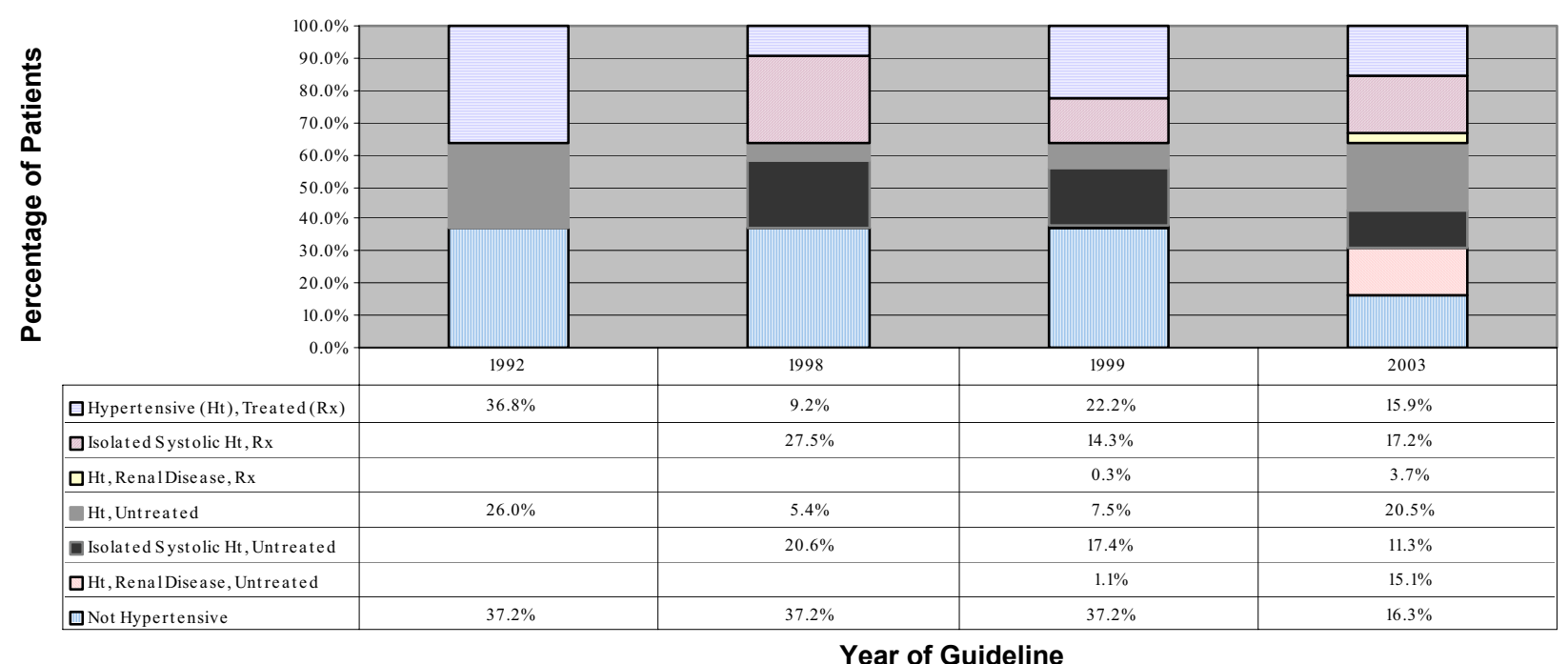

\section{Figure I}

The effect of clinical practice guidlines changes on the percentage of Nova Scotia patients with diabetes classified as hypertensive.

synonymously with the "Elderly" category used in the 1998 guidelines for data display purposes) Among all potential predictors of antihypertensive drug treatment related to the 2003 guidelines included in our database, only the patients receiving oral antihyperglycemics with or without insulin were more likely to be treated. (Table 1: Predictors of Treatment among Patients with Hypertension, 2003 Guidelines)

\section{Discussion}

Many Nova Scotia patients with diabetes mellitus had uncontrolled blood pressure and were not receiving antihypertensive medication. Achieving control of high blood pressure may be more important for long-term outcomes than glycemic control[3,10]. The rates were similar to other studies where 54-58\% were above target blood pressure and 22-28\% were not receiving antihypertensive treatment [24,25]. These populations have a decreased prevalence of hypertension, yet a higher rate of treatment in those affected.

Changing Clinical Practice Guidelines affect the criteria for diagnosis, the treatment targets, the population to be treated and the type of treatment. Many patients with diabetes mellitus previously considered to be normotensive are now above the defined cutpoints. Adherence to the newer guidelines would result in more patients being treated and increased drug expenditures, but may lead to decreased overall health service utilization and improved patient outcomes. Further work will be needed to determine the rate of adoption of the newer guidelines and the facilitators and barriers to adoption. For example, it is unclear how well guidelines apply to patients above age 85 or the frail elderly.

This study is a population-based study in the real world. The study included cardiovascular risk factors, and documentation of kidney disease unlike many survey reports[26]. Drug data was recorded by patient self-report at each visit by Diabetes Centre personnel. The quality of the DCPNS Registry evolved over time, particularly the details related to antihypertensive drug therapy. Selfreport has had good concordance with pharmacy claims data $[27,28]$. We were unable to determine how patients used the medications, if antihypertensive medications were used for hypertension or for another disease, any contraindications to therapy, the comorbid conditions, target organ damage, or response to previous antihypertensive therapy. Blood pressure measurements were part of routine care. Family history of cardiovascular disease, smoking, and lifestyle factors and the level of blood pressure at which treatment was started were not determined.

\section{Conclusion}

Many patients with diabetes mellitus and hypertension were not treated according to guidelines, with $47 \%$ of the patients meeting the 2003 guidelines definitions of hypertension not being treated with antihypertensive medica- 
Table I: Predictors of Treatment among Patients with Hypertension, 2003 Guidelines

\begin{tabular}{|c|c|c|}
\hline Variable & Crude Odds Ratio $(95 \% \mathrm{Cl})$ & Adjusted Odds Ratio $(95 \% \mathrm{Cl}) \dagger$ \\
\hline \multicolumn{3}{|l|}{ Age } \\
\hline$\leq 50$ & 1.00 & \\
\hline $51-60$ & $1.17(0.70-1.96)$ & \\
\hline $6 I-70$ & $\mathrm{I} .47(0.9 \mathrm{I}-2.37)$ & \\
\hline$\geq 71$ & $1.42(0.88-2.28)$ & \\
\hline \multicolumn{3}{|l|}{ Gender } \\
\hline Male & 1.00 & \\
\hline Female & $1.26(0.97-1.63)$ & \\
\hline \multicolumn{3}{|l|}{ Diabetes } \\
\hline Type I & $1.55(0.75-3.18)$ & \\
\hline Type II & 1.00 & \\
\hline \multicolumn{3}{|l|}{ Treatment $*$} \\
\hline Diet & 1.00 & 1.00 \\
\hline Oral meds & $1.89(1.31-2.74)$ & $1.89(1.31-2.74)$ \\
\hline Insulin & $\mathrm{I} .04(0.77-\mid .4 I)$ & $1.04(0.77-1.4 I)$ \\
\hline Insulin + Oral & $2.48(1.13-5.43)$ & $2.48(1.13-5.43)$ \\
\hline \multicolumn{3}{|l|}{ Kidney Disease ** } \\
\hline None & 1.00 & \\
\hline Mild & $1.32(0.90-1.94)$ & \\
\hline Moderate & $0.97(0.65-1.45)$ & \\
\hline Severe & $1.23(0.34-4.50)$ & \\
\hline Failure & not valid & \\
\hline \multicolumn{3}{|l|}{ Years Since Diagnosis } \\
\hline$\leq 5$ & 1.00 & \\
\hline $6-10$ & $0.86(0.62-1.19)$ & \\
\hline$\geq 11$ & $1.32(0.98-1.78)$ & \\
\hline
\end{tabular}

Years Since Referral

$\begin{array}{rl}\leq 3 & 1.00 \\ 4-7 & 0.84(0.61-1.17) \\ \geq 8 & 0.94(0.67-1.31)\end{array}$

Weight (KG)

$\begin{array}{ll}\leq 55 & 1.00 \\ 56-67 & 0.78(0.35-1.71) \\ 68-90 & 0.87(0.42-1.80) \\ \geq 91 & 0.99(0.47-2.06)\end{array}$

\footnotetext{
* Oral meds mean taking only oral antihyperglycemic medication; Insulin + Oral means patients who are taking insulin plus oral antihyperglycemic medication.

** Presence and stage of kidney disease as measured using the Cockroft-Gault formula.

† Treatment was the only significant predictor, and therefore is not adjusted.
}

tions. By reducing the cutpoints for defining hypertension, the proportion of people affected increased substantially. Specific risk factors determined may aid in identifying patients at high-risk for inadequate treatment. Patient and provider education, public health approaches, and health system changes are needed to address these issues. Further work is needed to determine the reasons for lack of control, approaches to improve control and long-term patient outcomes, and the budget impact and cost effectiveness of using the 2003 guidelines.

\section{Competing Interests}

The author(s) declare that they have no competing interests. 


\section{Authors' Contributions}

Cory Russell was involved with the design of the study, analysis and interpretation of the data, drafting and editing the manuscript, and gave final approval of the manuscript. All other authors were involved with the design of the study, interpretation of the data, editing and revising the manuscript, and gave final approval of the manuscript to be published.

\section{Financial Support}

Cory Russell was funded by the Drug Use Management and Policy Residency, a summer studentship that aims to build student and faculty understanding about how the creation of knowledge and dissemination of evidence is used by decision makers for drug used management and policy analysis. The Canadian Health Services Research Foundation, Canadian Institutes of Health Research and the Nova Scotia Health Research Foundation support this residency.

Dr. Ingrid Sketris holds a Chair funded by the Canadian Health Services Research Foundation(CHSRF)/Canadian Institutes for Health Research (CIHR) Chair in Health Services Research, co-sponsored by the Nova Scotia Health Research Foundation (NSHRF).

\section{Declaration of Business Interests/Disclaimer}

The data used in this research was made available by the Diabetes Care Program of Nova Scotia. Any opinions expressed by the authors do not necessarily reflect the opinion of DCPNS.

Presented in part at the 2004 Canadian Association for Population Therapeutics conference, June 6-8 2004 in Winnipeg, Mb

\section{Note}

The Effect of Clinical Practice Guidelines Changes on the Percentage of Nova Scotia Patients with Diabetes Classified as Hypertensive

\section{Acknowledgements}

The authors wish to thank Peggy Dunbar and Sonia Salisbury for participating as a preceptor in the Drug Use Management and Policy Residency. We are grateful to Charmaine Cooke, Jocelyn Leclerc, and Amanda Hayden, for their useful insights, support and help in the preparation of this manuscript.

\section{References}

I. Wolf HK, Andreou P, Bata IR, Comeau DG, Gregor RD, Kephart G, et al: Trends in the prevalence and treatment of hypertension in Halifax County from 1985 to 1995. CMAJ 1999, 161:699-704.

2. Meltzer S, Leiter L, Daneman D, Gerstein HC, Lau D, Ludwig S, et al.: 1998 clinical practice guidelines for the management of diabetes in Canada. In CMAJ Volume 159. Canadian Diabetes Association; 1998:SI-S29.

3. Johansen OE, Birkeland KI: Preventing Macrovascular Disease in patient with Type 2 Diabetes Mellitus. Am J Cardiovasc Drugs 2003, 3(4):283-297.
4. The UK Prospective Diabetes Study Group: Tight blood pressure control and risk of macrovascular and microvascular complications in type 2 diabetes. BM] 1998, 317:703-13.

5. Haffner SM: The importance of hyperglycemia in the nonfasting state to the development of cardiovascular disease. Endocr Rev 1998, 19(5):583-92.

6. Kannel WB, Mcgee DL: Diabetes and cardiovascular risk factors: the Framingham study. Circulation 1979, 59(I):8-13.

7. Joffres MR, Hamet P, MacLean DR, L'italien GJ, Fodor G: Distribution of blood pressure and hypertension in Canada and the United States. AJH 200I, 14:1099-I I05.

8. Dunbar, Peggy MEd, PDT, Coordinator for the Diabetes Care Program of Nova Scotia: Personal communication 2003.

9. Hansson L, Zanchetti A, Carruthers SG, et al.: Effects of intensive blood-pressure lowering and low-dose aspirin in patients with hypertension: principal results of the Hypertension Optimal Treatment (HOT) randomised trial. Lancet 1998, $351: 1755-1762$

10. Mogensen CE: Combined high blood pressure and glucose in type 2 diabetes: double jeopardy. BM] 1998, 3 17:693-4.

II. Chobanian AV, Bakris GL, Black HR, Cushman WC, Green LA, lzzo JL Jr, Jones DW, Materson BJ, Oparil S, Wright JT Jr, Roccella EJ, the National Heart, Lung, and Blood Institute Joint National Committee on Prevention, Detection, Evaluation, and Treatment of High Blood Pressure, the National High Blood Pressure Coordinating Committee: The Seventh Report of the Joint National Committee on Prevention, Detection, Evaluation, and Treatment of High Blood Pressure: the JNC 7 Report. JAMA 2003, 289( I 9):2560-2572.

12. Adler AI, Stratton IM, Neil HA, Yudkin JS, Mathhew DR, Cull CA, Wright AD, Turner RC, Holman RR: Association of systolic blood pressure with macrovascular and microvascular complications of type 2 diabetes (UKPDS 36): prospective observational study. $B M / 2000,321: 4|3-4| 9$.

13. Lewington S, Clarke R, Qizilbash N, Peto R, Collins R: Age-specific relevance of usual blood pressure to vascular mortality: a meta-analysis of individual data for one million adults in 61 prospective studies. Lancet 2002, 360:1903-1913.

14. Stamler J, Vaccaro O, Neaton JD, Wentworth D: Diabetes, other risk factors, and 12-yr cardiovascular mortality for men screened in the multiple risk factor intervention trial. Diabetes Care 1993, 16(2):434-444.

15. Carruthers SG, Hypertension in Gray J: Therapeutic Choices. Canadian Pharmacists Association 2000: $180-190$.

16. American Diabetes Association: Standards of Medical Care in Diabetes. Diabetes Care 2004:SI 5-35.

17. Canadian Diabetes Association Clinical Practice Guidelines ExpertCommittee: Canadian Diabetes Association Clinical Practice Guidelines for the Prevention and Management of Diabetes in Canada. Can J Diabetes 2003, 27(suppl 2):SI-SI 52.

18. Expert Committee of the Canadian Diabetes Advisory Board: Clinical practice guidelines for treatment of diabetes mellitus. CMAJ 1992, I47(5):697-7I2.

19. Feldman RD, et al.: Canadian Recommendations for the Management of Hypertension. CMAJ 1999, 16 1:SI-17.

20. Canadian Hypertension Education Program, [http:// www.hypertension.ca/Documentation/Recommendations2003.pdf]

21. Cockroft DW, Gault MH: Prediction of creatinine clearance from serum creatinine. Nephron 1976, 16:31-41.

22. Couchoud C, Pozet N, Labeeuw M, Pouteil-Noble C: Screening early renal failure: Cut-off values for serum creatinine as an indicator of renal impairment. Kidney Int 1999, 55(5): 1878-84.

23. World Health Organization Collaborating Centre for Drug Statistics Methodology: ATC Index with DDDs, 2002. Oslo, Norway: World Health Organization; 2002.

24. Toth EL, Majumdar SR, Guirguis LM, Lewanczuk RZ, Lee TK, Johnson JA: Compliance with Clinical Practice Guidelines for type 2 diabetes in rural patients: treatment gaps and opportunities for improvement. Pharmacotherapy 2003, 23:659-65.

25. Grant RW, Cagliero E, Murphy-Sheehy P, Singer DE, Nathan DM, Meigs JB: Comparison of hyperglycemia, hypertension, and hypercholesterolemia management in patients with Type 2 diabetes. Am J Med 2002, I I 2:603-9.

26. Wolf-Maier K, Cooper RS, Kramer H, Banegas JR, Giampaoli S, Joffres MR, Poulter N, Primatesta P, Stegmayr B, Thamm M: Hypertension 
treatment and control in five European countries, Canada, and the United States. Hypertension 2004, 43:10-17.

27. Kwon A, Bungay KM, Pei Y, Rogers WH, Wilson IB, Zhou Q, Adler DA: Antidepressant use: concordance between self-report and claims records. Med Care 2003, 4 I (3):368-74.

28. Saunders K, Simon G, Bush T, Grothaus L: Assessing the feasibility of using computerized pharmacy refill data to monitor antidepressant treatment on a population basis: a comparison of automated and self-report data. J Clin Epidemiol 1998, 5 I (I0):883-90.

Publish with Biomed Central and every scientist can read your work free of charge

"BioMed Central will be the most significant development for disseminating the results of biomedical research in our lifetime. " Sir Paul Nurse, Cancer Research UK

Your research papers will be:

- available free of charge to the entire biomedical community

- peer reviewed and published immediately upon acceptance

- cited in PubMed and archived on PubMed Central

- yours - you keep the copyright

Submit your manuscript here:

http://www.biomedcentral.com/info/publishing_adv.asp 